\title{
Range of normal values for left and right ventricular ejection fraction at rest and during exercise assessed by radionuclide angiocardiography
}

\author{
M. E. Pfisterer* ${ }^{*}$, A. BattLer $\dagger$ AND B. L. Zaret $\ddagger$ \\ * Division of Cardiology, Department of Internal Medicine, Division of Nuclear Medicine, Institute of \\ Radiology, University Hospital, Basel, Switzerland, + Division of Cardiology, The Chaim Sheba Medical \\ Center, Tel Hashomer, Israel and $¥$ Section of Cardiology and Nuclear Medicine, Yale University School of \\ Medicine, New Haven, CT, U.S.A.
}

KEY WORDS: Left ventricular function, regional left ventricular function, reproducibility, influence of age and sex on haemodynamics.

In order to reach a world-wide consensus on the normal range of left ( $L V)$ and right ventricular $(R V)$ ejection fraction (EF) at rest and during exercise, pooled data of 1200 normal subjects from 28 leading centres in the field of nuclear cardiology (68\% of those contacted) was analysed. Weighted mean normal values for LVEF at rest were $62 \cdot 3 \pm 6 \cdot 1 \%$ (ISD) with a lower limit of normal of $50 \%$ and for $R V E F$ $52.3 \pm 6.2 \%(\mathrm{~N}=365)$ with a lower limit of normal of $40 \%$. During exercise, LVEF increased in 475 subjects by $+8.0 \mathrm{EF} \%$ (range 3-15\%), a normal increase being accepted to be $\geqslant 5 \%$ over a normal resting value for both LVEF and RVEF. Subgroup analysis of results at rest revealed no significant differences regarding selection of normal subjects (based on normal catheterization findings vs. normal volunteers with low probability of disease), age or sex. During exercise, however, significantly larger increases in LVEF measurements were noted for men versus women $(\mathrm{P}<0.01)$, for normal volunteers versus subjects selected as 'normals' based on a normal coronary angiogram $(\mathrm{P}<0.001)$ and for younger versus older subjects $(\mathrm{P}<0.001)$. Data on reproducibility and variability showed that radionuclide angiocardiography can be considered to be a reliable method today. No consensus was found for measurements of regional LV function or wall motion mainly because of differences in methodology used. These normal values may serve cs general guidelines for future applications of these techniques but factors which may influence the normal range as defined and discussed in this study should be recognized.

Currently, radionuclide angiocardiography has become a widely used clinical method for assessing global and regional left (LV) and right ventricular (RV) function at rest and during physiologic stress $^{[1-4]}$. In order to set internationally acceptable standards for these procedures, the Council on Clinical Cardiology of the International Society and Federation of Cardiology and the World Health Organization appointed a Task Force on Nuclear Cardiology (appendix 1). One of the

Received for publication on 25 June 1984 and in revised form 2 May 1985.

This study was supported by the International Society and Federation of Cardiology and the World Health Organisation.

Address for reprints. M. Pfisterer, M.D., Division of Cardiology, Department of Internal Medicine, University Hospital, $\mathrm{CH}-4031$ Basel, Switzerland. charges of this Task Force was to define the normal range for nuclear cardiologic parameters of cardiac function. Factors which could account for differences in normal values between various laboratories include: definition of the 'normal' population employed, physiological parameters such as basal state at rest or type and intensity of exercise stress applied and the technical aspects of the different methodologies used. Despite such possible differences in performing radionuclide angiocardiography, a large amount of data on normal subjects has been reported in the literature $^{[1-7]}$ suggesting that a consensus can be reached concerning what is generally accepted to be 'within normal limits'. The aim of the present investigation was to provide such normal data of LV and RV function on a large scale international basis. 


\section{Principal considerations}

In developing a range of normal, several principal considerations would appear to be relevant. The definition of a 'normal' population is often based on normal findings at left heart catheterization but latent myocardial disease may be missed by anatomical and functional assessment only at rest ${ }^{(5,6,8]}$; the symptomatology responsible for invasive cardiac study may add to doubts whether such catheterization defines the "true normal'. Alternatively, clinically healthy volunteers with an extremely low probability of disease have been studied ${ }^{[9]}$; here 'hard data' concerning myocardial perfusion and coronary anatomy are missing, but the number of subjects with clinically hidden cardiac disorders is reduced. Both of these approaches have been used to define normal standards for radionuclide angiocardiography.

Physiologic parameters such as age, sex and body weight all may influence parameters of myocardial function ${ }^{[10-13]}$ and should be considered when normal values are defined. It is well known that physical training improves exercise performance $^{[14,15]}$ and that normal values may differ between athletes and sedentary people. Psychological imbalance, excitement or fear all affect the cardiovascular system in many ways ${ }^{[16]}$ and should be excluded in order to obtain resting measurements in a true basal state. Obviously, cardioactive medication may interfere with the assessment of normal function ${ }^{[17.18]}$. For 'exercise' measurements many additional factors have to be considered such as type of stress applied ${ }^{[19,20]}$, exercise protocol followed ${ }^{[21-23]}$, body position ${ }^{[24.25]}$ etc.

In addition, differences in normal values may arise from various methodological aspects. There might be differences between first pass and equilibrium (multiple gated) radionuclide function studies $^{[26]}$. Radioactive dose applied, acquisition time, acquisition equipment all may influence results. Even more important in everyday practice are type and reliability of data analysis (ranging from visual inspection to sophisticated computer programs) and the criteria used for interpretation of these results.

Despite this large number of variables influencing rest and exercise results, definition of the range of normal values as studies are currently performed would appear to be of considerable value - without eliminating the need for each institution to determine its own normal values based on its particular settings and protocol.

\section{Methods}

A questionnaire was sent to 41 representatives of leading centres in the field of nuclear cardiology worldwide selected by the Task Force asking 'What do you consider normal at your institution for routine nuclear cardiology procedures?' Each centre was asked to provide its own data and indicate exactly the definitions and methods used. Twenty-eight expert colleagues $(68 \%)$ returned the 5 page, 100 question survey, 15 from the United States of America, 10 from Europe and 3 from other parts of the world (Appendix 2). No response was received from 5 centres from the United States, 5 centres from Europe and 2 centres from other parts of the world. Questions ranged from methodology used and physiological variables observed to mean normal values with standard deviations, lower limit of normal and to specific problems such as the interpretation of a higher than normal ejection fraction (EF) at rest not changing during exercise.

Based on the results of this first survey, a second questionnaire was sent to all responding centres asking for additional and detailed information for LV and RV function at rest and during exercise for the following subgroups: (1) selection of the normal population (defined by normal catheterization findings $v s$. normal volunteers with low probability of disease), (2) gender (male vs. female), and (3) age ( $<30$ years, 31-40, 41-50, 51-60, >60 years). Additional questions concerned inter- and intraobserver variability, (physiological) variability over time and reproducibility of measurements.

Angiocardiographic results of 1200 'normal' subjects could be pooled to form a representative basis for normal standards. The number of patients contributed from each centre is shown in appendix 2. It was up to the expert colleagues in each centre to collect and describe their study population based on the available (retrospective) data base. Data of LVEF at rest was obtained from all 1200 subjects, whereas exercise results and values of RVEF were available from subgroups of 475 and 365 individuals, respectively.

\section{Analysis of results}

Answers on methodology were only analysed if at least $10(>1 / 3)$ institutions answered any particular question. Consensus was felt to be excellent if $>85 \%$ of answers agreed, good if at least two-thirds and fair if only $>50 \%$ agreed. 
Weighted mean normal values and average standard deviations were calculated for parameters of cardiac function taking into account number of subjects, mean value and standard deviation of each institution (cf. appendix 3$)^{[27]}$. The lower limit of normal defined as mean value minus 2 standard deviations was averaged from values used in each centre. For subgroup analysis, data of centres which provided no detailed information on the different subgroups were excluded, i.e., for example, if the results of a certain centre was based solely on men, these data were not included for the comparison between values of men and women. Significance of differences between groups was calculated according to the formula given in appendix 3 with a confidence limit of $95 \%(P<0.05)$; for differences between the multiple age groups, an analysis of variance test was applied.

\section{Results}

\section{LEFT VENTRICULAR EJECTION FRACTION AT REST}

Global LVEF at rest measured in the supine position in 1200 subjects from 24 centres after an average resting period of $14.8 \pm 12.2 \mathrm{~min}$ was $62.3 \%$ with a mean standard deviation of $\pm 6.1 \%$ (Table 1, Fig. 1). The lowest normal value reported was $53 \pm 6 \%$, the highest $70 \pm 7 \%$. The lower limit of normal was considered to be $51 \cdot 1 \pm 4 \cdot 2 \%$ (range $45-60 \%$ ). There was only a fair consensus on whether a 'hyperdynamic state' should be diagnosed in cases with a high resting $\mathrm{EF}$, this value lying above $76 \cdot 6 \pm 3 \cdot 8 \%$ (range $70-80 \%$ ).

There was no statistically significant difference between resting LVEF values for normals as

Table I Left ventricular ejection fraction at rest

\begin{tabular}{|c|c|c|c|c|}
\hline & $N$ & Mean & $\pm 1 \mathrm{SD}$ & $P$ \\
\hline Total & 1200 & $62 \cdot 3$ & $6 \cdot 1$ & \\
\hline $\begin{array}{l}\text { Selection: } \\
\text { cath normal } \\
\text { volunteers }\end{array}$ & $\begin{array}{l}386 \\
352\end{array}$ & $\begin{array}{l}62 \cdot 2 \\
60 \cdot 6\end{array}$ & $\begin{array}{l}9 \cdot 4 \\
6 \cdot 0\end{array}$ & NS \\
\hline $\begin{array}{l}\text { Sex: } \\
\text { men } \\
\text { women }\end{array}$ & $\begin{array}{r}214 \\
86\end{array}$ & $\begin{array}{l}62 \cdot 1 \\
64.9\end{array}$ & $\begin{array}{l}7.8 \\
6.1\end{array}$ & NS \\
\hline $\begin{array}{l}\text { Age: } \\
\quad \leqslant 30 \\
31-40 \\
41-50 \\
51-60 \\
.>60\end{array}$ & $\begin{array}{l}58 \\
97 \\
77 \\
90 \\
74\end{array}$ & $\begin{array}{l}61 \cdot 1 \\
63.6 \\
62.9 \\
62.2 \\
66.4\end{array}$ & $\begin{array}{l}5.8 \\
7.6 \\
6.1 \\
7.3 \\
8.5\end{array}$ & $\begin{array}{c}\text { NS } \\
{[<60 v s>60,} \\
P<0.001]\end{array}$ \\
\hline
\end{tabular}

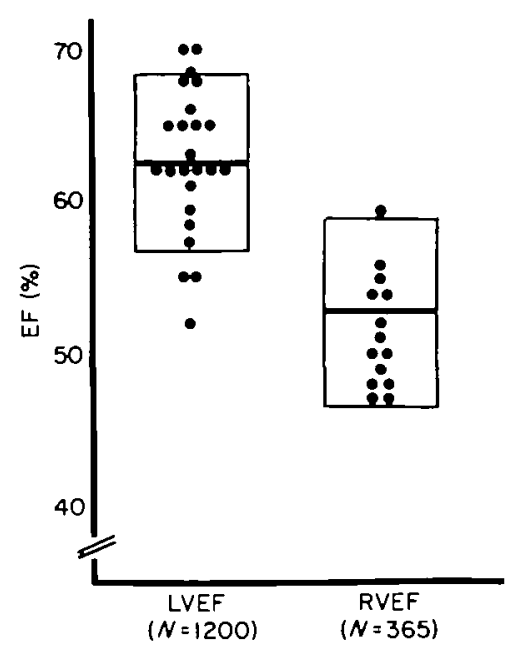

Figure I Normal values for left and right ventricular ejection fraction at rest. Bars indicate weighted mean values $\left(\bar{x}_{w}\right) \pm 1$ weighted mean standard deviation $\left(\mathrm{SD}_{*}\right)$, dots represent mean values of different centres.

defined by catheterization findings $(62 \cdot 2 \pm 9 \cdot 4 \%$, $N=386$ ) vs. normal volunteers with low probability of disease $(60.6 \pm 6.0 \%, N=352)$. Furthermore, there were no significant differences in normal LVEF at rest in sex and age subgroups, except for subjects older than 60 years whose resting LVEF was $66 \cdot 4 \pm 8.5 \%$ vs. $62.6 \pm 6.9 \%$ in patients less than 60 years $(P<0.001)$ (Table 1). Most values reported were based on gated blood pool studies (85\%) acquired over $4.4 \pm 1.0 \mathrm{~min}$ using an automated computer algorhythm (70\%) with a variable $L V$ region of interest $(91 \%$ of answers). There was no significant difference between normal values obtained with first pass or gated equilibrium techniques.

\section{LEFT VENTRICULAR EJECTION FRACTION DURING EXERCISE}

During exercise (supine in $67 \%$ ) which had to be symptom-limited ( 24 of 25 answers) or at least attained $85 \%$ maximal heart rate (18 of 24 answers), a good consensus was found concerning a normal change in left ventricular function: $E F$ had to increase $\geqslant 5$ absolute EF percent over a normal resting value in 18 of 26 centres whereas 4 responders felt that a larger, 2 that a smaller increase and 2 that no fall below a normal resting value were normal criteria. Based on a study in 60 subjects with normal catheterization findings, one laboratory felt that due to the wide variation of EF responses to exercise, no 'normal' change could 
be defined ${ }^{[7]}$ but the data of this laboratory was included, too. The mean change in LVEF during exercise of 475 subjects was $+8.0 \%$ (range $3-15 \%$ ) (Table 2, Fig. 2). Normal volunteers with low probability of coronary artery disease increased their LVEF significantly more than subjects defined as normals based on normal coronary angiographic findings $(+8.6$ vs. $+4.7 \% ; P<0.001)$. Similarly, the exercise-induced rise in LVEF was

Table 2 Change in left ventricular ejection fraction during exercuse

\begin{tabular}{|c|c|c|c|c|}
\hline & $N$ & Mean & $\pm 1 \mathrm{SD}$ & $P$ \\
\hline Total & 475 & +8.0 & 7.65 & \\
\hline $\begin{array}{l}\text { Selection: } \\
\text { cath normal } \\
\text { volunteers }\end{array}$ & $\begin{array}{l}224 \\
191\end{array}$ & $\begin{array}{l}+4.7 \\
+8.6\end{array}$ & $\begin{array}{l}9 \cdot 1 \\
7 \cdot 1\end{array}$ & $<0.001$ \\
\hline $\begin{array}{l}\text { Sex: } \\
\quad \text { men } \\
\text { women }\end{array}$ & $\begin{array}{r}128 \\
50\end{array}$ & $\begin{array}{l}+10 \cdot 5 \\
+5 \cdot 3\end{array}$ & $\begin{array}{l}7.0 \\
8.7\end{array}$ & $<0.01$ \\
\hline $\begin{array}{l}\text { Age: } \\
\qquad 30 \\
31-40 \\
41-50 \\
51-60 \\
>60\end{array}$ & $\begin{array}{l}56 \\
48 \\
62 \\
40 \\
36\end{array}$ & $\begin{array}{l}+12.5 \\
+11.8 \\
+8.5 \\
+8.6 \\
+7.6\end{array}$ & $\begin{array}{l}4 \cdot 4 \\
5 \cdot 2 \\
6 \cdot 6 \\
5 \cdot 8 \\
7 \cdot 3\end{array}$ & $<0.001$ \\
\hline
\end{tabular}

significantly larger in men than in women $(+10 \cdot 5$ vs. $+5.3 \% ; P<0.01)$. Finally, there was a gradual and significant decline of the rise in LVEF during exercise with age $(P<0.001)$ (Table 2$)$.

In $73 \%$ of responders who used the gated blood pool technique the data was acquired during a 2 min exercise period. There was good agreement that clearly submaximal exercise tests had to be interpreted cautiously, results being of questionable relevance. Only 14 of 26 responders felt that a LVEF of $75 \%$ at rest not changing during exercise was still a normal finding.

\section{RIGHT VENTRICULAR EJECTION FRACTION AT REST}

Normal values for RVEF were reported from 14 centres covering 365 subjects studied with first pass and equilibrium radionuclide techniques (in 7 centres each). Mean normal values at rest were $52.3 \%$ ranging between 47 and $59 \%$ with an average standard deviation of $\pm 6.2 \%$ (Table 3 ). The lower limit of normal was considered to be $40 \cdot 7 \pm 3 \cdot 1 \%$ (range $35-45 \%$ ). Twenty-two of 26 responders are using visual interpretation of $\mathrm{RV}$ function alone or in addition to calculation of EF.

No significant differences between RVEF values at rest for normal subjects as defined by normal catheterization findings $(51 \cdot 0 \pm 5 \cdot 0 \%, N=81)$ vs. normal volunteers with low probability of disease $(49 \cdot 0 \pm 5 \cdot 0 \%, N=64)$ were found. Again, there

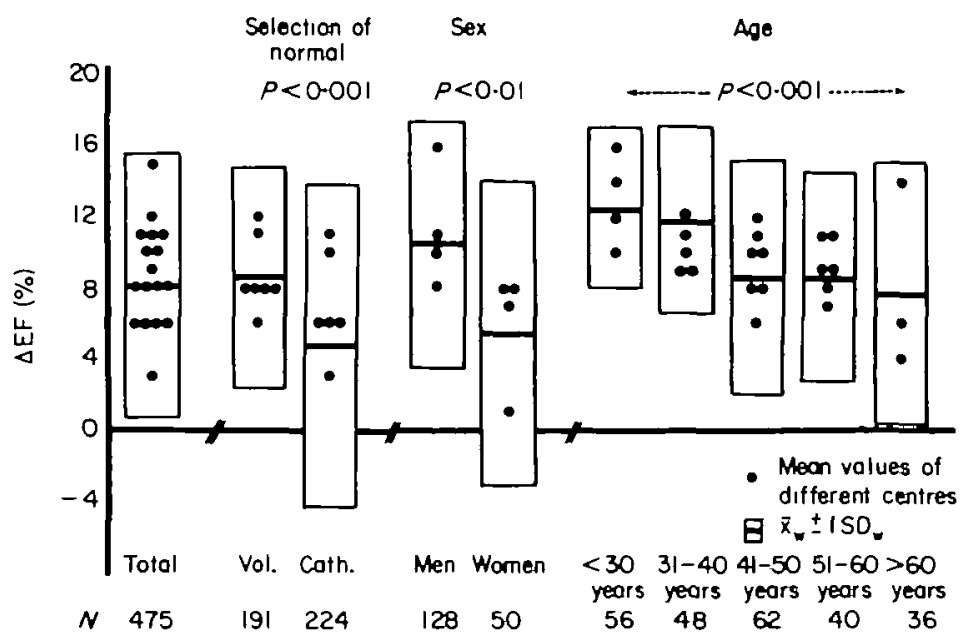

Figure 2 Normal change in LVEF from rest to symptom-limited exercise and its relation to selection of normal, sex and age subgroups. Bars indicate weighted mean values $\left(\overline{\mathrm{x}}_{\mathrm{w}}\right) \pm 1$ weighted mean standard deviation (SD, ), dots represent mean values of different centres [cath. - normal subjects as defined by normal coronary angiograms; vol. - normal subjects as defined by low probability of disease (volunteers)]. 
Table 3 Right ventricular ejection fraction at rest

\begin{tabular}{|c|c|c|c|c|}
\hline & $N$ & Mean & $\pm 1 S D$ & $P$ \\
\hline Total & 365 & $52 \cdot 3$ & $6 \cdot 2$ & \\
\hline $\begin{array}{l}\text { Selection: } \\
\text { cath normal } \\
\text { volunteers }\end{array}$ & $\begin{array}{l}81 \\
64\end{array}$ & $\begin{array}{l}51 \cdot 0 \\
49 \cdot 1\end{array}$ & $\begin{array}{l}5.0 \\
5.0\end{array}$ & NS \\
\hline $\begin{array}{l}\text { Sex: } \\
\quad \text { men } \\
\text { women }\end{array}$ & $\begin{array}{r}17 \\
3\end{array}$ & $\begin{array}{l}48.0 \\
49.0\end{array}$ & $\begin{array}{l}5 \cdot 0 \\
5 \cdot 0\end{array}$ & NS \\
\hline $\begin{array}{l}\text { Age: } \\
\quad<30 \\
31-40 \\
>41\end{array}$ & $\begin{array}{l}13 \\
42 \\
14\end{array}$ & $\begin{array}{l}49.0 \\
50.6 \\
47.1\end{array}$ & $\begin{array}{l}5 \cdot 0 \\
5 \cdot 7 \\
4 \cdot 1\end{array}$ & NS \\
\hline
\end{tabular}

were no significant differences in mean normal values assessed by first pass or equilibrium angiocardiographic techniques $(52 \cdot 1 \%$ vs. $52 \cdot 3 \%)$ but no intra-patient or intra-centre comparative data were available. The same is true for age and sex subgroups, but here the groups were too small to draw definite conclusions (Table 3 ).

RIGHT VENTRICULAR EJECTION FRACTION DURING EXERCISE

During exercise, RVEF is accepted to increase by at least 5 absolute EF percent over a normal resting value by most laboratories which quantitate $R V E F$ routinely. In addition, $R V$ function is generally assessed by visual interpretation of radionuclide data displayed in movie format (19 of 22 laboratories).

\section{REPRODUCIBILITY OF MEASUREMENTS}

Interobserver variability of LVEF for repeat analysis of the same data was small (range of $1 \mathrm{SD} \pm 1.4 \%$ to $\pm 5.0 \%$, mean $\pm 2.6 \% ; N=558$ ) as was intraobserver variability (range of $1 \mathrm{SD}$ $\pm 1.0 \%$ to $\pm 3.0 \%$, mean $\pm 2.3 \% ; N=548$; Table 4). Variability of LVEF over time, i.e. in repeated acquisitions with an interval of $15 \mathrm{~min}$ to 14 days was good, too: $\pm 3.6 \%$ (range of $1 \mathrm{SD} \pm 1.6 \%$ to $\pm 10.0 \% ; N=164$ ) resulting in a mean correlation coefficient for reproducibility of $r=0.95$ (range $r=0.77$ to $r=0.99$ ) for EF values ranging from very low to high normal.

Inter- and intra-observer variability of RVEF was about $1 \%$ larger than that for LVEF (Table 4), resulting in a reproducibility of these measurements with $r$-values between 0.80 and 0.98 (mean 0.92).
Table 4 Variability of measurements

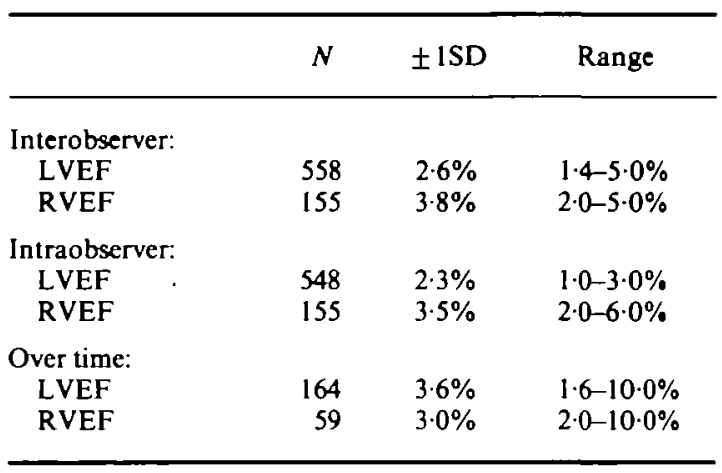

\section{REGIONAL LEFT VENTRICULAR FUNCTION/WALL MOTION}

Regional LV function or wall motion is assessed in all 28 centres by visual interpretation of cinefilms in movie-format. Only in 13 centres is regional EF calculated regularly and three centres use numerical values for comparison of rest/ intervention studies only. There was only a fair agreement regarding the method used to calculate regional EF: a majority of those answering use radial sectors from a centre of gravity or mass. Due to the different analyses applied it was not possible to reach a consensus on normal values for regional EF. It is noteworthy, however, that in six of seven laboratories with detailed results, regional function was lowest in the septal area as compared to infero-apical and posterolateral regions.

\section{Discussion}

As part of an attempt to describe the state of the art of radionuclide angiocardiography today, the spread of normal values used in 28 leading centres in the field of nuclear cardiology was compiled and analysed in this study. The observed range of normal values may serve as a guideline for future applications of this technique and help in comparisons of data obtained by these methods in different laboratories. Important factors influencing normal values, especially during exercise, were defined such as age, sex, selection of a normal population as well as the study protocol used. Although it has to be stressed that calculated mean normal values originating from different centres may be open to debate from a strictly statistical point of view, it seems that knowledge of the 
range of normal values observed world-wide is of considerable clinical importance. The large number of EF values collected which to our knowledge are unprecedented by any published analysis of normal haemodynamic data outweigh some of the inherent problems of such a multicentre investigation based on a questionnaire.

Based on the present survey, a world-wide consensus on the range of normal values for LVEF and RVEE could be obtained. According to these results and in the absence of clinical signs of heart disease, LVEF $\geqslant 50 \%$ (mean $62.3 \pm 6.1 \%$ ) and RVEF $\geqslant 40 \%$ (mean $52.3 \pm 6.2 \%$ ) may be considered normal at rest; during symptom-limited exercise, an increase of at least 5 absolute EF percent over a normal resting value describe a normal change for both ventricles. These findings are valid only in the absence of any cardioactive medication. With the methodology used today, these values can be obtained with low variability and high reproducibility. Certain factors which may influence the normal range, especially during exercise, such as definition of normal, age, sex and study protocol used have to be recognized.

\section{FACTORS INFLUENCING LEFT VENTRICULAR FUNCTION}

Subgroup analysis of LV (and RV) function at rest showed no significant differences regarding selection of normal subjects, gender and methodology used, except for subjects older than 60 years who had a somewhat higher LVEF than those below age 60 . It seems most likely that this difference was due to the selection process which is probably most important in the older age group. The assurance of a basal state at rest with which exercise values can be compared appears to be important since the higher the EF at rest, the less its increase with exercise $\mathrm{e}^{[7]}$. This point is underlined by the relatively large 'physiologic' variability of EF measurements over time described here and reported previously ${ }^{[28]}$.

In contrast, during exercise significantly larger increases in LVEF measurements were found for men $v s$. women, for normal volunteers $v s$. subjects selected as 'normals' based on normal coronary angiographic findings and for younger vs. older subjects (Fig. 2). A decline in the LVEF response to exercise with increasing age has recently been reported by Port and coworkers who found no change or even a decrease in the EF during exercise in most subjects above age $60^{[29]}$. In the present pooled data a more gradual decline was noted and there was still a significant exercise-induced increase in LVEF in the age group $>60$ years. Possible mechanisms for this age-associated decrease in EF response to exercise include decreased contractility due to aging ${ }^{[30]}$ or silent myocardial disease which is more frequent at higher age ${ }^{[31]}$, increased afterload with higher age $^{[32]}$, lower exercise heart rate ${ }^{[33-35]}$ and lower maximal work load attained by older individuals ${ }^{[36]}$. Unfortunately, the data base of the present investigation did not allow us to differentiate between these factors, but it has been demonstrated that LVEF is dependent on changing loading conditions of the heart ${ }^{[37]}$. It should be noted, however, that the present findings parallel results of haemodynamic parameters such as maximal work capacity, oxygen consumption, cardiac output, stroke volume and left ventricular filling pressures during exercise in relation to age ${ }^{[10,13.38,39]}$. The causes for the sex differences found in the present study remain speculative, too, but again, the differences parallel sex-related differences in maximal work capacity and haemodynamic variables reported ${ }^{[12,40,41]}$.

\section{CHEST PAIN AND NORMAL CORONARY ANGIOGRAM}

The EF response to exercise in patients with chest pain but angiographically normal coronary arteries represents another important issue. This group may represent an as yet undefined new pathophysiologic entity rather than 'true' normals. Berger et al. observed LV dysfunction despite normal resting performance in a substantial number of such patients with chest pain, an ischaemicappearing exercise electrocardiogram and normal coronary arteries ${ }^{[42]}$. Maddahi et al. ${ }^{[9]}$ found objective signs of exercise-induced ischaemia more frequently in subjects with normal coronary arteriograms as compared with an alternative population with less than $1 \%$ likelihood of coronary artery disease suggesting presence of disease despite normal coronary arteries. Such considerations may explain the significantly lower rise in EF during exercise found in the present study in subjects selected as normals based on a normal coronary angiogram $v s$. the higher increase in normal volunteers. This interpretation is supported by a follow-up study of angiographically normal subjects which demonstrated that incipient heart disease may be present in subjects in whom coronary angiographic examination has removed a previous suspicion of coronary artery disease ${ }^{[43]}$. The selection process has also been shown to cause 
an apparent decline in specificity of exercise radionuclide angiocardiography in recently studied patients as compared with those studied when the technique was first introduced ${ }^{[44]}$. Rozanski and coworkers $^{[44]}$ felt that differences in the selection and definition of 'normal' individuals during the two time periods could account for differences in specificity (referral bias), since recently studied patients had a markedly higher pretest probability of coronary artery disease as opposed to those studied earlier.

\section{NORMAL RIGHT VENTRICULAR FUNCTION}

There is less data on RV function at rest and during exercise. We noted a good agreement in these normal values despite the different methods used. Although first pass radionuclide angiocardiography may be the preferred method to assess RVEF, the equilibrium technique seems to provide comparable normal values; the limits of this method might be more apparent in various disease states where the different cardiac structures may not be as easily separated as in normal subjects. A comparative validation of both techniques was, however, beyond the scope of this investigation. Reproducibility and variability of RVEF determination was somewhat worse than that for LVEF as assessed here and reported earlier ${ }^{\text {(45.46] }}$, but still well within acceptable limits, most likely due to manually outlined RV regions-of-interest vs. observer-independent edge-detection programs used for $\mathrm{LV}$ regions ${ }^{[47]}$.

\section{REGIONAL LEFT VENTRICULAR FUNCTION}

No consensus could be reached for regional EF or shortening measurements due to the multitude of analyses used ${ }^{[48-51]}$. Therefore all responding centres still use a visual and subjective interpretation of wall motion disorders in addition to or instead of quantitative measurements. These differences in methodology between the various laboratories suggest that no one optimal solution has been described or accepted to date. It was interesting to note, however, that in 6 of 7 laboratories with detailed analyses, regional function of the left ventricle was lowest in the anteroseptal area as compared with the inferoapical and posterolateral regions, which may either be due to the left anterior oblique projection used for analysis or to the interaction with the right ventricle.

\section{Conclusions}

In conclusion, this investigation demonstrated that radionuclide angiocardiography is a highly reproducible method for the assessment of LVEF and RVEF. A world-wide consensus on the range of normal values at rest and during exercise could be reached based on pooled data of 1200 normal subjects. These normal values may serve as general guidelines for future applications of these techniques, but factors which may influence the normal range as defined and discussed in this study should be recognized.

We appreciate the excellent statistical support given by J. E. Dowd, statistician, Epidemiological and Statistical Methodology, World Health Organization, Geneva, Switzerland. We also thank C. Faes for her secretarial assistance.

\section{References}

[1] Bodenheimer MM, Banka VS, Helfant RH. Nuclear cardiology I. Radionuclide angiographic assessment of left ventricular contraction: uses, limitations and future directions. Am J Cardiol 1980; 45: 661-73.

[2] Okada RD, Boucher CA, Strauss HW, Pohost GM. Exercise radionuclide imaging approaches to coronary artery disease. Am J Cardiol 1980; 46: 1188-204.

[3] Berman DS, Mason DT (eds). Clinical nuclear cardiology. New York: Grune and Stratton, 1981: 187-320.

[4] Pfisterer M. Nuklearmedizinische Herzdiagnostik. Kliniktaschenbücher. Berlin: Springer-Verlag, 1980: 4-38.

[5] Borer JS, Kent KM, Bacharach SL et al. Sensitivity, specificity and predictive accuracy of radionuclide cineangiography during exercise in patients with coronary artery disease. Circulation 1979; 60: 572-80.

[6] Pfisterer ME, Slutsky R, Schuler G et al. Profiles of radionuclide left ventricular ejection fraction changes induced by supine bicycle exercise in normals and patients with coronary heart disease. Cathet Cardiovasc Diagn 1979; 5: 305-17.

[7] Gibbons RJ, Lee KL, Cobb F, Jones RH. Ejection fraction response to exercise in patients with chest pain and normal coronary arteriograms. Circulation 1981; 64: 952-7.

[8] Lichtlen PR. Hemodynamics of clinical ischemic heart disease. Ann Clin Res 1971; 3: 333-45.

[9] Maddahi J, Rozanski A, Becerra A et al. Patients with a calculated very low likelihood of coronary artery disease: an alternative population of cardiac normals. Circulation 1982; 66 (II): 62 (Abstr).

[10] Julius S, Amery A, Whitlock LS, Conway J. Influence of age on the hemodynamic response to exercise. Circulation 1967; 36: 222-30.

[11] Gerstenblith G, Lacatta EG, Weisfeldt M. Age changes in myocardial function and exercise response. Prog Cardiovase Dis 1976; 19: 1-21.

[12] Buonanno C, Arbustini E, Rossi L et al. Left ventricular function in men and women. Another difference between sexes. Eur Heart J 1982; 3: 525-8.

[13] Ehrsam RE, Perruchoud A, Oberholzer M, Burkart F, Herzog $H$. Influence of age on pulmonary haemodynamics at rest and during supine exercise. Clin Sci 1983; 65: 653-60. 
[14] Barnard RJ, McAlpin R, Cattus AA, Buckberg GD. Effect of training on myocardial oxygen supply/ demand balance. Circulation 1977; 56. 289-91.

[15] Rerych SK, Shulz PM, Sabiston DC, Jones RH. Effects of exercise traning on left ventricular function in normal subjects: a longitudinal study by radionuclide angiography. Am J Cardiol 1980;45 244-52.

[16] Hackett TP, Rosenbaum JF. Emotion, psychiatric disorders and the heart. In: Braunwald E, ed. Heart disease. Philadelphia: SB Saunders Co, 1980; 1923-41.

[17] Battler A, Ross J Jr, Slutsky R, Pfisterer M, Ashburn W, Froelicher V. Improvement of exercise-induced left ventricular dysfunction with oral propranolol in patients with coronary heart disease. Am J Cardiol 1979; 44: 318-24.

[18] Pfisterer M, Glaus L, Burkart F. Comparative effects of nitroglycerine, nifedipine and metoprolol on regional left ventricular function in patients with one vessel coronary disease. Circulation 1983; 67: 291-301.

[19] Slutsky, R. Response of the left ventricle to stress: effects of exercise, atrial pacing, afterload stress and drugs. Am J Cardiol 1981; 47: 357-64.

[20] Jordan LJ, Borer JS, Zullo M et al. Exercise versus cold temperature stimulation during radionuclide cineangiography: diagnostic accuracy in coronary antery disease. Am J Cardiol 1983; 51: 1091-7.

[21] Astrand PO, Cuddy TE, Saltin B, Steinberg J. Cardiac output during submaximal and maximal work. J Appl Physiol 1964; 19: 268-74.

[22] Sorrensen SG, Ritchie JL, Caudwell JH, Hamilton GW, Kennedy JW. Serial exercise radionuclide angiography. Validation of count-derived changes in cardiac output and quantitation of maxımal exercise ventricular volume change after nitroglycerin and propranolol in normal men. Circulation 1980; 61: 600-9.

[23] Brady TJ, Thrall JH, Pitt B. The importance of adequate exercise in the detection of coronary heart disease by radionuclide ventriculography. J Nucl Med 1980; 21: 1125-30.

[24] Poliner LR, Dehmer GJ, Levis SE, Parkey RW, Blomqvist CG, Willerson JT. Left ventricular performance in normal subjects: a comparison of the responses to exercise in the upright and supine positions. Circulation 1980; 62: 528-34.

[25] Freeman MR, Berman DS, Staniloff $\mathrm{H}$ et al. Comparison of upright and supine bicycle exercise in the detection and evaluation of the extent of coronary artery disease by equilibrium radionuclide ventriculography. Am Heart J 1981; 102: 182-9.

[26] Kaul S, Boucher CA, Okada RD, Newell JB, Strauss HW, Pohost GM. Sources of vanability in the radionuclide angiographic assessment of ejection fraction: a comparison of first-pass and gated equilibrium techniques. Am J Cardiol 1984; 83: 823-8.

[27] Cochran WG. The combination of estimates from different experiments. Biometrics 1954; 10: 101-29.

[28] Wackers FJC, Berger HJ, Johnstone DE et al. Multiple gated cardiac blood pool imaging for left ventricular ejection fraction: validation of the techniques and assessment of variability. Am J Cardiol 1979; 43: $1159-66$.

[29] Port S, Cobb FR, Coleman E, Jones RH. Effect of age on the left ventricular ejection fraction response to exercise. N Engl J Med 1980; 303: 1133-6.
[30] Templeton GH, Platt MR, Willerson JT, Weisfeldt $M L$. Influence of aging on left ventricular hemodynamics and stıffness in beagles. Circ Res 1979; 44: $189-94$.

[31] White NK, Edwards JE, Dry TJ. The relationship of the degree of coronary atherosclerosis with age in man. Circulation 1950; 1. 645-51.

[32] Yin FCP, Spurgeon HA, Greene HL, Lakatta EG, Weisfeldt ML. Age-associated decrease in heart response to isoproterenol in dogs. Mech Aging Dev 1979; 10: 17-25.

[33] Robinson S. Experimental studies of physical fitness in relation to age. Arbe1tsphysiologie 1938; 10: 251-323.

[34] Bruce RA, Hornsten RT. Exercise stress testing in evaluation of patients with ischemic heart disease. Prog Cardiovasc Dis 1969; 11: 371-90.

[35] Pfisterer M, Burkart F. Test zur Bestimmung der kōrperlichen Lesstungsfāhigkeit drei Wochen nach Myokardinfarkt. Z Kardiol 1975; 64: 1143-53.

[36] Raven PB, Mitchell JH. Effect of aging on the cardiovascular response to dynamic and static exercise. In: Weisfeldt $M L$, ed. The aging heart: its function and response to stress. New York: Raven Press, 1980; 28 : 473-A.

[37] Mahler F, Ross J Jr, O'Rourke RA, Covell JW. Effect of changes in preload, afterload and inotropic state on ejection and isovolumic phase of measures of contractility in the conscious dog. Am J Cardiol 1975; 35: 626-34.

[38] Ástrand I, Ástrand P-O, Hallbäck I, Kilbom A. Reduction in maximal oxygen uptake with age. J Appl Physiol 1973; 35: 649-73.

[39] Robinson S, Dill DB, Ross JC, Robinson RD, Wagner $\mathrm{JA}$, Tzankoff SP. Training and physiological aging in man. Fed Proc 1943; 32: 1628-56.

[40] Astrand I. Aerobic work capacty in men and women with special reference to age. Acta Physiol Scand 1960; 49 (Suppl 169): 11-92.

[41] Burkart F, Pfisterer M. Bicycle ergometry during the first weeks after early mobilization in 600 patients with myocardial infarction. In: Early mobilization and exercise testing after myocardial infarction. König $\mathbf{K}$, ed. Monheim: Pharma Schwarz, 1980: 57-64.

[42] Berger HJ, Sands MJ, Davies RA el al. Exercise left ventricular performance in patients with chest pain, ischemic-appearing exercise electrocardiograms and angiographically normal coronary angiograms. Ann Intern Med 1981; 94: 186-91.

[43] Erikssen J, Dale J, Rootwelt K, Myhre E. False suspicion of coronary heart disease: a 7 year followup study of 36 apparently healthy middle-aged men. Circulation 1983; 48: 490-7.

[44] Rozanski A, Diamond GA, Berman D, Forrester JS, Morris D, Swan HJC. The declining specificity of exercise radionuclide ventriculography. $\mathrm{N}$ Engl J Med 1983; 309: 518-22.

[45] Pfisterer M, Battler A, Swanson SM, Slutsky R, Froelicher V, Ashburn WL. Reproducibility of ejection fraction determinations by equilibrium radionuclide angiography in response to supine bicycle exercise. $J$ Nucl Med 1979; 20: 491-5.

[46] Upton MP, Rerych SK, Newman GE, Bounous EP, Jones RH. The reproducibility of radionuclide angiographic measurements of left ventricular function in normal subjects at rest and during exercise. Circulation $1980 ; 62: 126-32$. 
[47] Slutsky R, Pfisterer M, Verba J, Battler A, Ashburn W. Infuence of different background and left ventricular assignments on ejection fraction in equilibrium radionuclide angiography. Radiology 1980; 135: 725-30.

[48] Brady TJ, Thrall HJ, Keyes JW, Brymer JF, Walton JF, Pitt B. Segmental wall-motion analysis in the right anterior oblique projection: comparison of exerciseequilibrium radionuclide ventriculography and exercise contrast ventriculography. J Nucl Med 1980; 21: 617-21.

[49] Maddox DE, Winne J, Uren R et al. Regional ejection fraction: a quantitative radionuclide index of regional left ventricular performance. Circulation 1979; 59 . 1001-9.

[50] Papapietro SE, Yestro MV, Logic JR et al. Method for quantutative analysis of regional left ventricular function with first pass and gated blood pool scintigraphy. Am J Cardiol 1981; 47: 618-25.

[51] Pfisterer $M$, Emmenegger $H$. Non-invasive quantification of exercise-induced changes in regional left ventricular function in normals and patients with one vessel coronary artery disease using radionuclide ventriculography. Eur Heart J 1982; 3: 203-11.

\section{Appendix 1}

TASK FORCE ON NUCLEAR CARDIOLOGY

A. Battler, Tel-Hashomer, Israel

H. Berger, New Haven, USA

M. Bodenheimer, Philadelpha, USA

J. Borer, New York, USA

M. Brochier, Tours, France

M. Pfisterer, Basel, Switzerland

B. Zaret, New Haven, USA (chairman)

\section{Z. Pisa, Geneva, Switzerland, WHO}

P. Hugenholtz, Rotterdam, The Netherlands, ISFC

H. Neufeld, Tel Hashomer, Israel, ISFC

E. Rapaport, San Francisco, USA, ISFC

\section{Appendix 2}

PARTICIPATING CENTRES - in parenthesis: number of subjects

\section{Europe}

University of Liege, Belgium (10)

University Hospital, Nancy, France (*)

University Hospital, Tours, France (12)

University Hospital, Goettingen, Germany (25)

University Hospital, Heidelberg, Germany (30)

University Hospital, Munich, Germany (30)

St Bartholomew's Hospital,.London, Great Britain (150)

University Hospital, Basel, Switzerland (20)

University Hospital, Geneva, Switzerland (25)

Thoraxcenter, Erasmus University, Rotterdam, Netherlands (*)

\section{United States of America}

University of Michigan, Ann Arbor, Michigan (50)

National Institution of Health, Bethesda, Maryland and New York Hospital, New York (53)

- Harvard Medical School, Boston, Massachusetts (22)

University of Vermont, Burtington, Vermont (42)

Duke University, Durham, North Carolina (300)

University of Texas, Houston, Texas (25)
UCLA, Los Angeles, California (16)

Mount Sinai Medical Center, Milwaukee, Wisconsin (*)

Yale University, New Haven, Connecticut (45)

Columbia University, New York, New York (21)

VA Medical Center, Oklahoma City, Oklahoma (55)

Presbyterian-University Medical Center, Philadelphia (24)

University Hospital, San Diego, California (75)

UCSF, San Francisco, California (30)

VA Hospital, Seattle, Washington (20)

\section{Other}

Royal Prince Alfred Hospital, Sydney, Australia (30)

Cardiovascular Center, Osaka, Japan (50)

Heart Institute, Tel Hashomer, Israel (40)

(*Answers only regarding methodology; no detailed results)

\section{Appendix 3}

Weighted mean values were calculated according to the formula:

$$
\bar{x}_{w}=\frac{1}{w} \sum_{i=1}^{k} \bar{x}_{i} \cdot w_{i}
$$

where

$$
w=\sum_{i=1}^{k} w_{1}
$$

and

$$
w_{i}=\left(\frac{n_{i}}{n_{0}}\right)\left(\frac{\sigma_{0}}{\sigma_{1}}\right)
$$

with

$\mathrm{n}_{0}=$ total no. of subjects,

$k=$ no. of centres,

$\mathrm{n}_{1}=$ no. of subjects in the $\mathrm{i}$-th centre,

$x_{1}=$ mean of centre $i$,

$\overline{\mathbf{x}}_{\mathbf{w}}=$ weighted mean value,

$\sigma_{i}=$ standard deviation of centre 1 ,

$\sigma_{0}=$ standard deviation pooled over all centres, $\sigma_{0}=\left(\sigma^{2} / \mathbf{k}\right)^{1 / 2}$

Weighted mean values for the standard deviation were calculated as:

$$
\sigma_{w}=\sum_{i=1}^{k}\left(\frac{n_{1}}{n_{0}}\right)\left(\frac{\bar{x}_{0}}{\bar{x}_{i}}\right) \sigma_{i}
$$

where

$$
\overline{\mathbf{x}}_{0}=\frac{1}{k} \sum_{i=1}^{k} \overline{\mathbf{x}}_{\mathbf{i}} .
$$

Subgroup differences were calculated according to the formula:

$$
t \text {-value }=\frac{\text { difference in mean values }}{\text { standard error of difference }}
$$

where

standard error of difference $=\left(\frac{\sigma_{\sigma_{1}}^{2}}{n_{0.1}}+\frac{\sigma_{\sigma^{2}}^{2}}{\mathrm{n}_{0.2}}\right)^{12}$,

1,2 = subgroups,

$\mathrm{n}_{0,1}=$ total no. of subjects in subgroup $\mathrm{i}$. 